\title{
Environmentally friendly road asphalt mixtures
}

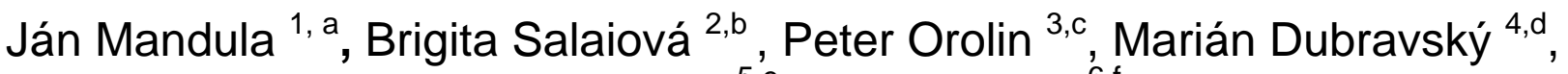 \\ Tomáš Olexa ${ }^{5, e}$, Olga Frolova ${ }^{6, f}$ \\ ${ }^{1-6}$ Technical university of Košice, Civil engineering faculty, Department of geotechnics and traffic \\ engineering, Vysokoškolská 4, 04200 Košice, Slovakia

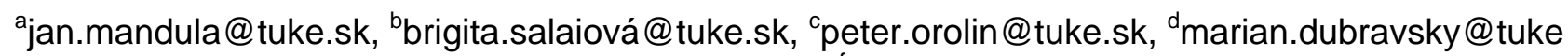 \\ .sk, 'tomas.olexa@tuke.sk, olga.frolova@tuke.sk
}

Keywords: natural zeolite, stiffness, noise, asphalt.

\begin{abstract}
In recent years, roads are deteriorated due to increasing traffic volumes, and they require extensive reconstruction which should be environmentally friendly. This can be done by using new additives and waste and recycled materials in road construction. Recently developed warm mix asphalt technology decreases impact on environment. One of the materials which make it possible to lower production temperature of asphalt mixtures is natural zeolite, which is incorporated into asphalt mixtures in the production process. New asphalt mixtures, however, shall comply with standard requirements for the physical and mechanical properties and the conditions for resistance of the layers and therefore the stiffness modulus of these mixtures has to be measured. One of the other environmental aspects is noise pollution in urban areas, which negatively affects and endangers human health. One of the ways how to suppress this negative phenomenon is to develop new materials for road surfaces taking into account their economic, environmental and quality aspects.
\end{abstract}

\section{Introduction}

The paper deals with the addition of natural zeolite and crumb rubber into asphalt mixtures used for road surface layer, which is the essential part of the road construction. The measurements carried out are focused on the characterization of basic physical - mechanical properties which are reported in the European standards valid also in Slovakia.

\section{Warm mix asphalt (WMA) production technology}

WMA technologies work at temperatures above $100^{\circ} \mathrm{C}$, so that the remaining amount of water in the mixture is very small. In order to reduce the effective viscosity of the binder different technologies are used which allow complete aggregate coating and reasonable compactibility at lower temperatures. They are based on:

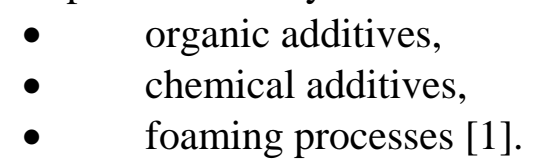

Technologies based on foaming processes. This technology is based on the addition of a small amount of water which is injected either into the hot binder, or directly into the mixing chamber. When the water is mixed with the hot asphalt, high temperature causes that water evaporates. This creates a large volume of foam, which temporarily increases the volume of the binder and decreases the viscosity of mixture. This effect remarkably improves the mix workability but its duration is limited. This means that the mixture has to be transported and compacted as soon as possible after production. Although the basic procedure is the same for most of these products and technologies, the ways in which water is added to the production cycle may vary [2]. 


\section{Natural zeolite}

The structure of clinoptilolite consists of three-dimensional framework which consists of silicate tetrahedra $\left(\mathrm{SiO}_{4}\right)_{4}$ - interconnected via oxygen atoms; a part of silicon atoms is replaced by aluminum forming $\left(\mathrm{AlO}_{4}\right)_{5-}$ which creates characteristic spatial structure with significant occurrence of cavities, interconnected by channels, in which metal cations, or water molecules reside. The volume of these cavities can amount from 24 to $32 \%$ of the crystal volume.

The extensive uses of zeolites are mainly due to their specific physical-mechanical properties:

0 high selectivity and ion exchange,

o reversible hydration and dehydration,

o high gas sorption capacity,

o high thermostability,

o resistance to aggressive media [3, 7].

\section{Physical-mechanical properties}

Three asphalt mixtures were prepared for experimental study. The first one was a reference mixture with no additives compacted at $145^{\circ} \mathrm{C}$ (AC $11 \mathrm{O}$ Ref). The second one was asphalt concrete (AC $11 \mathrm{O}$ ) with $1.25 \%$ of crumb rubber compacted at $145^{\circ} \mathrm{C}$. The third one was warm mix asphalt concrete (WMA AC $11 \mathrm{O}$ ) with $0.3 \%$ of natural zeolite compacted at $125{ }^{\circ} \mathrm{C}$. The density of tested asphalt mixtures and void content for each mixture are shown in Fig. 1. All mixtures comply with European standard.

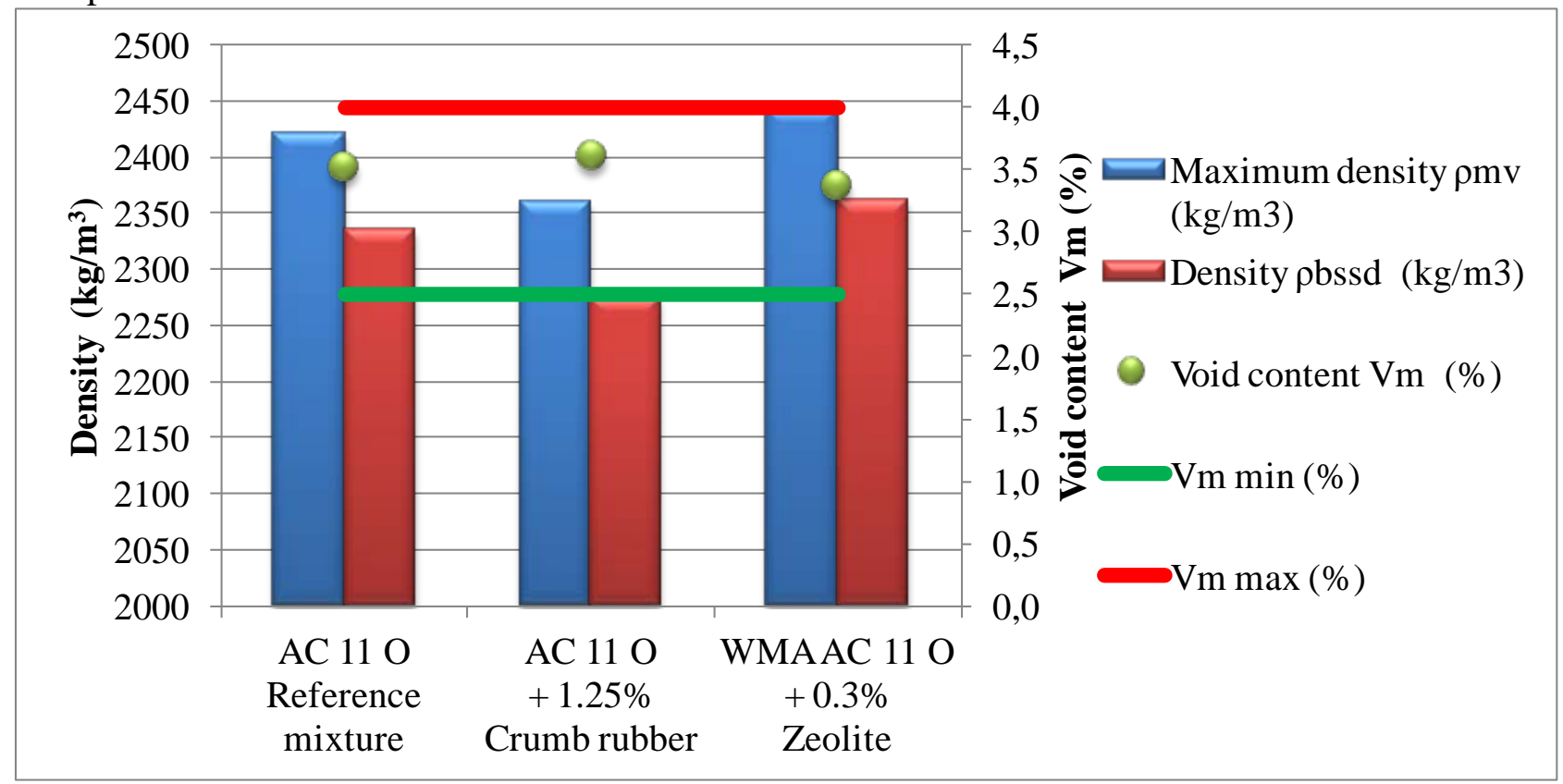

Fig. 1 Physical and mechanical properties

\section{Qualitative comparison}

Nowadays a few researches at the Technical University of Košice are focused on development of asphalt mixtures in combination with different additives. This paper presents warm mix asphalt with zeolite addition which is compared with other modified asphalt mixtures, e.g., mixtures with recycled asphalt or with rubber particles obtained from used tires.

The quality of mixtures was estimated using stiffness modulus as the main parameter. The stiffness modulus was measured on Marshall samples (EN 12697 - 30) which could be used only to illustrate differences of resistance between chosen mixtures. The conditions of measurement were specified according to standard (EN 13108 - 20) for the method of indirect measurement of tensile stiffness (IT-CY) $[4,5]$. The temperature was set to $20^{\circ} \mathrm{C}$ and the load was applied in shape of 
haversine. The loading pulse period was $124 \mathrm{~ms}$ which could be defined as loading frequency of $8 \mathrm{~Hz}$ and repetition pulse period was 3 seconds. For each mixture five samples were tested to get reasonable results. The next step in our testing was the use of four point bending apparatus for stiffness modulus measurement on the samples prepared by roller compactor or gyrator. The results and conditions of testing are listed in Table 1.

Table 1. Stiffness modulus of studied asphalt mixtures

\begin{tabular}{|ll|c|c|c|}
\hline Type of mixture: & $\begin{array}{c}\text { AC 11 O Reference } \\
\text { mixture }\end{array}$ & $\begin{array}{c}\text { AC 11 O } \\
+1.25 \% \text { Crumb rubber }\end{array}$ & $\begin{array}{c}\text { WMA AC 11 O } \\
+0.3 \% \text { Zeolite }\end{array}$ \\
\hline Stiffness Modulus & {$[\mathrm{MPa}]$} & 4946 & 3758 & 4842 \\
\hline Temperature & {$\left[{ }^{\circ} \mathrm{C}\right]$} & 20 & 20 & 20 \\
\hline Frequency & {$[\mathrm{Hz}]$} & 8 & 8 & 8 \\
\hline
\end{tabular}

All mixtures had the same conditions of testing. The values of stiffness modulus are slightly different but in general upper limit is $5000 \mathrm{MPa}$ which is comparable with other types of asphalt mixture with the same test temperature. All studied asphalt mixtures are suitable for using in surface layer of the road. The best results were obtained for the reference mixture and the sample with zeolite addition which has only a slightly different value of stiffness modulus. The difference between these two mixtures is about $100 \mathrm{MPa}(2.0 \%)$, which could be within uncertainty of laboratory procedure. On the other hand the sample with addition of crumb rubber has a lower value of stiffness modulus by $1200 \mathrm{MPa}$ which is $24 \%$ difference in comparison with the reference mixture. The obtained results suggest that using of zeolite is suitable not only for the base layers but also for the surface layers where the specific value of stiffness modulus is required.

\section{Measurement of acoustic properties of road surface containing crumb rubber}

The use of used tires in asphalt rubber mixes can help in waste tires disposal. The results of traffic noise levels measurements prove that chosen mixtures with crumb rubber have comparable or better properties than traditional asphalt mixes. The old surface course was removed on the experimental section of the road and replaced by asphalt concrete with addition of crumb rubber in amount $1.25 \%$ of aggregate weight. The experimental section of the road is $200 \mathrm{~m}$ long and pavement is laid in 40 mm thick layer.

The measurements of traffic noise levels were carried out on the experimental road section of Kosice region in April 2014. The results of measurements were compared with the reference values reported in ISO 11819-1. The measurements were based on the SPB method (Statistical Pass-By method). The SPB method is an exact method for evaluation of the noise caused by the tire-pavement contact. It takes into account also other influences such as noise which arises from the power-train. The measurement procedure and the choice of measurement location were in accordance with the instructions described in ISO 11819-1 and [6].

For each vehicle the maximum of noise level during passing near the microphone was measured, the speed of the vehicle and its length were measured as well. The next step of processing was to normalize data. Then the SPBI (Statistical Pass-By Index) was calculated. Statistical Pass-By Index (SPBI) listed in Table 2, was calculated in order to assess the influence of road pavements on sound pressure levels [6].

Table 2. Statistical Pass-By Index calculated for each type of road surface

\begin{tabular}{|c|c|}
\hline Type of road surface & $\begin{array}{c}\text { Statistical Pass-By Index } \\
\text { SPBI, (dB) }\end{array}$ \\
\hline AC 11 O with 1.25\% crumb rubber & 71.42 \\
\hline Reference pavement & 77.57 \\
\hline
\end{tabular}




\section{Conclusion}

Warm mix asphalt enables asphalt industry to improve performance of their products, to increase efficiency of construction and to obtain environmental benefits. The results of laboratory measurements show that the asphalt mixture with the addition of $0.3 \%$ of natural zeolite has similar physical and mechanical properties as a hot mix asphalt compacted at elevated temperatures. Superior acoustic properties were observed for the pavement with crumb rubber modified asphalt mixture when compared with the reference pavement, the noise level was lower by $6.15 \mathrm{~dB}$. The results of measurements showed decrease in sound pressure level at the roads which went through the exchange of original covers by the crumb rubber modified bitumen. In order to maintain a good performance of these roads in terms of noise pollution their constant maintenance and cleaning pores of the covers are necessary.

\section{Acknowledgment}

Article is the result of the Project implementation: University Science Park TECHNICOM for Innovation Applications Supported by Knowledge Technology, ITMS: 26220220182, supported by the Research \& Development Operational Programme funded by the ERDF.

\section{References}

[1] TOPAL A., SENGOZ B., KOK BV.: Evaluation of mixture characteristics of warm mix asphalt involving natural and synthetic zeolite additives. In: Construction and building materials, Volume: 57, P. 38-44, ISSN: 0950-0618

[2] DRÜSCHNER L.: Experience with Warm Mix Asphalt in Germany. Sonderborg: NVF-rapporter, 2009, guest report in conference

[3] RUBIO CM., MARTINEZ G., BAENA L., MORENO F.: Warm mix asphalt: an overview. Journal of Cleaner Production, Volume 24, March 2012, P. 76-84. ISSN: 0959-6526

[4] MODARRES A., HAMEDI H.: Developing laboratory fatigue and resilient modulus models for modified asphalt mixes with waste plastic bottles (PET). In: Construction and Building Materials Journal: Volume 68, 15 October 2014, P. 259-267. ISSN 0950-0618

[5] MORENO - NAVARRO F., SOL-SANCHEZ M.: The use of additives for the improvement of the mechanical behavior of high modulus asphalt mixes. In: Construction and Building Materials Journal: Volume 70, 15 November 2014, P. 65-70. ISSN: 0950-0618 - eISSN: 1879-0526

[6] MUN S., CHO DS.: Determination of the sound power levels emitted by various vehicles using a novel testing method: ELSEVIER SCI LTD 2008; ISSN: 0003-682X

[7] DUBRAVSKÝ M., MANDULA J.: Technology of warm mix asphalt based on foaming processes. SGEM 2013: 13th International Multidisciplinary Scientific Geoconference: Ecology, Economics, Education and Legislation: conference proceedings: Volume 1, Albena, Bulgaria. Sofia: STEF92 Technology Ltd., 2013 P. 913-919. ISBN 978-619-7105-04-9, ISSN 1314-2704 